\title{
Stimulation of the P6 Acupuncture Point for Prophylaxis of Nausea and Vomiting in Pregnant Women Submitted to Cesarean Section: A Blinded Clinical Trial
}

\author{
Luiza Helena Castelo Branco, Luciana Cavalcante Lima, Maria Célia Ferreira Costa, \\ Marilia Santos Lira, Raquel Queiroz Guerra de Andrade Coelho, Tania Cursino de Menezes Couceiro*, \\ Anne Danielle Soares, Eusa Maria Belarmino Alcoforado, Maria Emilia Carvalho
}

Instituto de Medicina Integral Prof. Fernando Figueira (IMIP), Recife, Brazil.

Email: *taniacouceiro@yahoo.com.br

Received December $6^{\text {th }}, 2012$; revised April 18 ${ }^{\text {th }}, 2013$; accepted May $6^{\text {th }}, 2013$

Copyright (C) 2013 Luiza Helena Castelo Branco Branco et al. This is an open access article distributed under the Creative Commons Attribution License, which permits unrestricted use, distribution, and reproduction in any medium, provided the original work is properly cited.

\begin{abstract}
In pregnant women subjected to spinal anesthesia for a Cesarean section, episodes of nausea and vomiting are common both during and following surgery. Acupuncture for the prophylaxis and treatment of these complications has been gaining in popularity due to its low cost, simplicity, absence of side effects and confirmed efficacy. This study investigated the efficacy of stimulating the P6 acupoint in conjunction with the use of dexamethasone as prophylaxis for nausea and vomiting in pregnant women submitted to spinal anesthesia for a Cesarean section. The patients $(\mathrm{n}=100)$ were randomly distributed into two groups. In the first group $(\mathrm{n}=50)$, a site located one centimeter laterally from P6 was stimulated. This is not a true acupuncture point (sham acupuncture). In the second group ( $=50)$, P6 was stimulated. In both groups, $4 \mathrm{mg}$ of dexamethasone were administered intravenously. A questionnaire was used to obtain information on the occurrence of nausea and vomiting during surgery and in the first 12 hours postpartum. The chi-square test and Fisher's exact test were used to assess differences between the groups. Age and physical status were similar in both groups. The incidence of nausea during surgery was $32 \%(n=16)$ in the control group and $22 \%(n=11)$ in the P6 group ( $p>0.05)$. In the first 12 hours following surgery, nausea occurred in $16 \%$ of the women in the control group $(n=6)$ and in $4 \%$ in the P6 group $(n=4)(p=0.045)$. The incidence of vomiting in the control group was $12 \%(n=6)$ during surgery and $10 \%(n=5)$ in the postoperative period compared to $8 \%(n=4)$ and $4 \%(n=2)$, respectively, in the P6 group $(p>0.05)$. Although these differences were not statistically significant with the exception of the incidence of nausea in the first 12 hours postpartum, a reduction occurred in the incidence of all the outcomes evaluated in the P6 group.
\end{abstract}

Keywords: Obstetric Surgery; Cesarean Section; Complications; Nausea; Vomiting; Prophylaxis; Acupuncture

\section{Introduction}

Nausea and vomiting remain common complications both during and following surgery despite research and the development of new drugs and techniques [1]. Although often considered a trivial problem, in some cases these symptoms may lead to significant morbidity, since they can provoke aspiration pneumonitis, electrolyte disorders, dehydration and an increase in postoperative pain [1-3].

The risk factors for the development of the abovementioned symptoms in adults in the postoperative period include: being female, young and pregnancy $[4,5]$.

${ }^{*}$ Corresponding author.
In pregnant women submitted to spinal anesthesia for a Cesarean section, episodes of nausea and vomiting are complications that may occur both during (intra-operative nausea and vomiting-IONV) and following surgery (postoperative nausea and vomiting-PONV). The etiology is multifactorial, involving the physiological changes that occur during pregnancy, intraoperative hypotension, increased vagal activity, visceral stimulation, and the effect of neuraxial opioid administration and the use of oxytocin [6].

The incidence of nausea and vomiting during and following procedures in which spinal anesthesia is used for surgical delivery ranges from $28 \%$ to $63 \%$ and remains high despite the introduction of new antiemetic drugs 
[7-9]. In the population submitted to general surgical procedures, the incidence of PONV is $20 \%-30 \%$ and in patients considered to be at a high risk for PONV, this incidence may reach as high as $70 \%-80 \%$ [4].

Based on this concept of a multifactorial etiology, in recent years a multimodal antiemetic management has been defended in which combinations of drugs and techniques with different mechanisms of action are used to optimize efficacy $[4,5]$. Of the various techniques and drugs available for the prophylaxis and treatment of nausea and vomiting, those involving non-pharmacological methods have been increasing in popularity due to their low cost, simplicity, lack of side effects, confirmed efficacy and furthermore, they involve a characteristic that is extremely important in obstetrics: they are not transferred through the placenta and are not secreted in breast milk [6].

Of these techniques, acupuncture, through stimulation of the P6 acupuncture point (Pericardium 6 or the Neiguanacupoint) [10-15]. This point is on the inside of the arm, about 2 cum widths above the wrist crease, between the tendons of the flexor carpi radialis and palmarislongus muscles. The person measuring the point needs to use the width of the pregnant woman's fingers to provide the correct measurement. Needles must be inserted to a depth of $0.8-1.0$ tsun.

Various physiological mechanisms have been proposed to explain the antiemetic effect of P6 stimulation, such as: stimulation of the endogenous opioid system, serotonin release, increased vagal modulation, direct stimulation of the visceral smooth muscle and stimulation of the somatovisceral and somatosympathetic reflexes that affect the lower esophageal sphincter and gastric relaxation [6].

The objective of the present study was to evaluate the efficacy of the P6 acupoint as a prophylactic treatment of nausea and vomiting in the 12 hours postpartum in pregnant women submitted to Cesarean section under spinal anesthesia.

\section{Methods}

A random and comparative clinical trial was conducted with 100 pregnant women classified as P1 or P2 in accordance with the American Society of Anesthesiologists (ASA) submitted to Cesarean section. This study was approved by the Institution Research Ethics Committee. After having signed the informed Consent Form patients were distributed into two groups using sealed envelopes: the control group ( $\mathrm{n}=50$ ), received $4 \mathrm{mg}$ of dexamethasone (standard prophylaxis at this institute) associated with stimulation of a site located one centimeter laterally from P6. This is not a true acupuncture point (sham acupuncture) and was used in order to make the interventions more uniform and the P6 group $(n=50)$ received dexamethasone associated with stimulation of the P6 acupoint. Stimulation was performed on the upper limb homolateral to the one used for venous puncture, using a filiform needle with a diameter that ranged from 0.8 to 1.0 cun, inserted for a period of 20 minutes.

Exclusion criteria were: the presence of hemodynamic instability, altered consciousness, a history of alcohol or drug abuse, allergy or hypersensitivity to the drugs used in the study, relative or absolute contraindications to spinal anesthesia and the presence of nausea or vomiting prior to initiating the procedure.

No preanesthetic medication was administered. Monitoring consisted of cardioscopy, pulse oximetry and intermittent noninvasive blood pressure monitoring. Peripheral venous access was obtained using an 18- or 20gauge catheter. Spinal anesthesia was the anesthetic technique used in all cases and it was performed by the resident physician under the supervision. With the patient in the seated or left lateral decubitus position, the subarachnoid space was identified using a 25- or 27-gauge Quincke needle inserted into the L2-L3 or L3-L4 spaces. As soon as the cerebrospinal fluid was seen to be dripping, 12 $14 \mathrm{mg}$ of hyperbaric bupivacaine together with $0.06 \mathrm{mg}$ of morphine were administered. The patient was then placed into the dorsal decubitus position, slightly inclined towards the left until satisfactory anesthesia was obtained (sensorial block at the level of T6 or above), at which time surgery was initiated. Hydration was performed with a crystalloid solution. Stimulation of P6 or sham P6 was performed by the resident physician who was adequately trained by an anesthesiologist specialized in acupuncture. The variables analyzed were: age, ASA Physical status and nauseas and vomiting intraoperative and postoperative in the 12 hours postpartum.

It was estimated that to achieve an $80 \%$ power to detect a difference (0.05) and based on a previous study [5] which found that non-pharmacologic acupoint technics were superior to the placebo at preventing early nausea $(\mathrm{RR}=0.34)$ and early vomiting $(\mathrm{RR}=0.47)$ in adults, 36 patients would be required in each group. Assuming a dropout rate of $30 \%$ we planned to recruit 50 patients to each group.

\section{Results}

No patient was excluded after randomization. The sample showed similar results concerning the age and ASA physical status. The incidence of nausea during surgery was $32 \%(n=16)$ and $22 \%(n=11)$ in the control and P6 groups, respectively $(\mathrm{p}>0.05)$. In the first 12 hours following surgery, the incidence of nausea was $16 \%$ in the control group ( $(n=6)$ and $4 \%$ in the P6 group $(n=4)$, the difference between the groups was statistically significant $(p=0.045)$ (Figure 1). The incidence of vomiting in 


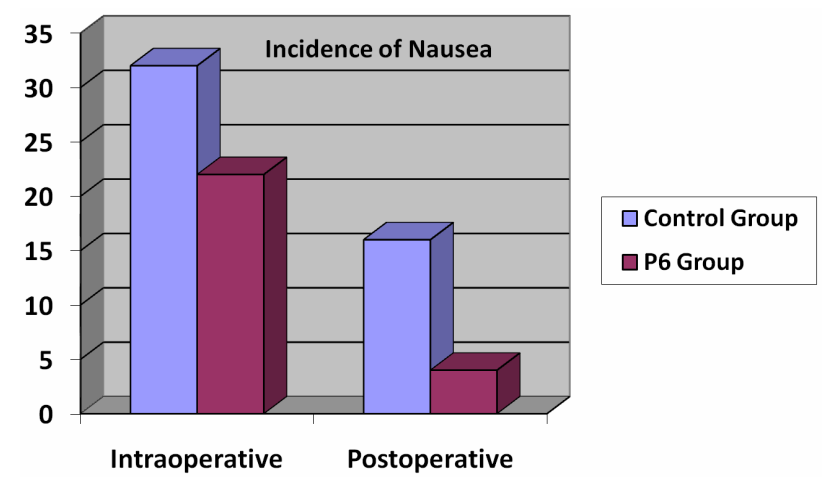

Figure 1. Incidence of nausea during and following surgery according to treatment group.

the control group was $12 \%(\mathrm{n}=6)$ during surgery and $10 \%(n=5)$ in the postoperative period, whereas in the P6 group, 8\% $(\mathrm{n}=4)$ suffered vomiting during surgery and $4 \%(\mathrm{n}=2)$ following surgery $(\mathrm{p}>0.05)$ (Figure 2). There was no statistically significant difference between the two groups.

After randomization no patient was excluded. There were no statistically significant differences between the two groups with respect to age or physical status. The incidence of nausea during surgery was $32 \%(n=16)$ and $22 \%(\mathrm{n}=11)$ in the control and P6 groups, respectively $(\mathrm{p}>0.05)$. In the first 12 hours following surgery, the incidence of nausea was $16 \%$ in the control group $(n=6)$ and $4 \%$ in the P6 group $(\mathrm{n}=4)$, this difference being statistically significant $(p=0.045)$ (Figure 1). On the other hand, the incidence of vomiting in the control group was $12 \%(n=6)$ during surgery and $10 \%(n=5)$ in the postoperative period, whereas in the P6 group, $8 \%(n=4)$ suffered vomiting during surgery and $4 \%(n=2)$ following surgery ( $p$ 0.05) (Figure 2).

\section{Discussion}

The main findings of this study were that the stimulation of the P6 acupoint was an effective prophylactic treatment of nauseain the 12 hours postpartumin pregnant women submitted to spinal anesthesia for cesarean section. This population is at higher risk of developing IONV and PONV when compared to non-pregnant women [1,2]. For this reason, some authors recommend the routine use of prophylactic drugs and this approach is not without risks and may result in an undesired increase in costs and lead to the occurrence of side effects [13].

Moreover, the advantages of P6 stimulation as an antiemetic include its low cost, simplicity, the absence of side effects, and the fact that it cannot be transferred through the placenta or secreted in breast milk $[6,16]$.

However, in our study the P6 stimulation was not effective in prevent vomiting. The possible explanation for

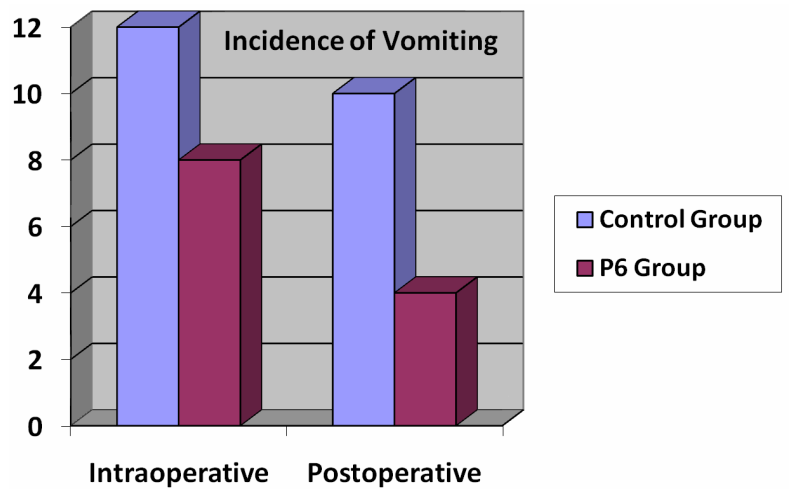

Figure 2. Incidence of vomiting during and following surgery according to treatment group.

this finding is that we used low doses of opioids and astrict control of the blood pressure [17], therefore diminishing the incidence of IONV and PONV.

Metoclopramide in pregnant women was discontinued in our Institution due to the evidence of its inefficacy as a prophylactic agent and the potential risk of extrapyramidal effects. These adverse effects can cause considerable discomfort and often make it impossible for the woman to care for her newborn infant [16]. In our institution the care of the newborn is provided by the mother and the absence of nausea and vomiting can contribute to make the newborn care more pleasant. For this reason, any approach that diminishes PONV e IOPNV is justifiable for this specific population.

In conclusion, stimulation of the P6 acupoint, associated with the use of dexamethasone reduced the incidence of nausea in the first 12 hours postpartum. There was a reduction in the incidence of all the outcomes evaluated in the P6 group, although these differences were not statistically significant.

\section{REFERENCES}

[1] M. N. Mendes, R. S. Monteiro and F. A. Martins, "Prophylaxis of Postoperative Nausea and Vomiting in Morbidly Obese Patients undergoing Laparoscopic Gastroplasties. A Comparative Study among Three Methods," Revista Brasileira de Anestesiologia, Vol. 59, No. 5, 2009, pp. 570-576. doi:10.1590/S0034-70942009000500005

[2] M. Arnberger, K. Stadelmann, P. Alischer, R. Ponert, A. Melber and R. Greif, "Monitoring of Neuromuscular Blockade at the P6 Acupuncture Point Reduces the Incidence of Postoperative Nausea and Vomiting,” Anesthesiology, Vol. 107, No. 6, 2007, pp. 903-908. doi:10.1097/01.anes.0000290617.98058.d9

[3] C. A. Patti, J. E. Vieira and F. E. Bensenõr, "Incidence and Prophylaxis of Nausea and Vomiting in Post-Anesthetic Recovery in a Tertiary Teaching Hospital,” Revista Brasileira de Anestesiologia, Vol. 58, No. 5, 2008, pp. 462469. 
[4] T. J. Gan, T. A. Meyer, C. C. Apfel, F. Chung, P. J. Davis, A. S. Habib, V. D. Hooper, A. L. Kovac, P. Kranke, P. Myles, B. K. Philip, G. Samsa, D. I. Sessler, J. Temo, M. R. Tramèr, C. Vander Kolk and M. Watcha, "Society for Ambulatory Anesthesia Guidelines for the Management of Postoperative Nausea and Vomiting," Anesthesia and Analgesia, Vol. 105, No. 6, 2007, pp. 1615-1628. doi:10.1213/01.ane.0000295230.55439.f4

[5] C. Nunley, J. Wakim and C. Guinn, "The Effects of Stimulation of Acupressure Point P6 on Postoperative Nausea and Vomiting: A Review of Literature," Journal of Perianesthesia Nursing, Vol. 23, No. 4, 2008, pp. 247261. doi:10.1016/j.jopan.2008.05.001

[6] T. K. Allen and A. S. Habib, "P6 Stimulation for the Prevention of Nausea and Vomiting Associated with Cesarean Delivery under Neuraxial Anesthesia: A Systematic Review of Randomized Controlled Trials,” Anesthesia and Analgesia, Vol. 107, No. 4, 2008, pp. 1308-1312. doi:10.1213/ane.0b013e31816d1864

[7] J. B. Dahl, I. S. Jeppesen, H. Jørgensen, J. Wetterslev and S. Møiniche, "Intraoperative and Postoperative Analgesic Efficacy and Adverse Effects of Intrathecal Opioids in Patients Undergoing Cesarean Section with Spinal Anesthesia: A Qualitative and Quantitative Systematic Review of Randomized, Controlled Trials,” Anesthesiology, Vol. 91, No. 6, 1999, pp. 1919-1927. doi:10.1097/00000542-199912000-00045

[8] Y. Fujii, H. Tanaka and H. Toyooka, "Prevention of Nausea and Vomiting with Granisetron, Droperidol and Metoclopramide during and after Spinal Anesthesia for Caesarean Section: A Randomized, Double-Blind, PlaceboControlled Trial," Acta Anaesthesiologica Scandinavica, Vol. 42, No. 8, 1998, pp. 921-925. doi:10.1111/j.1399-6576.1998.tb05350.x

[9] M. A. Chaney, "Side Effects of Intrathecal and Epidural Opioids,” Canadian Journal of Anaesthesia, Vol. 42, No. 10, 1995, pp. 891-903. doi:10.1007/BF03011037

[10] A. S. Habib, N. Itchon-Ramos, B. G. Phillips-Bute, T. J. Gan and Duke Women's Anesthesia (DWA) Research Group, “Transcutaneous Acupoint Electrical Stimulation with the Relief Band ${ }^{\circledR}$ for the Prevention of Nausea and Vomiting during and after Cesarean Delivery under Spinal Anesthesia,” Anesthesia and Analgesia, Vol. 102, No.
2, 2006, pp. 581-584. doi:10.1213/01.ane.0000189217.19600.5c

[11] P. E. Scuderi, "P6 Stimulation: A New Approach to an Ancient Technique,” Anesthesiology, Vol. 107, No. 6, 2007, pp. 870-872. doi:10.1097/01.anes.0000291438.04166.84

[12] Y. C. Arai, N. Kato, M. Matsura, H. Ito, N. Kandatsu, S. Kurokawa, M. Mizutani, Y. Shibata and T. Komatsu, "Transcutaneous Electrical Nerve Stimulation at the PC-5 and PC-6 Acupoints Reduced the Severity of Hypotension after Spinal Anesthesia in Patients Undergoing Caesarean Section,” British Journal of Anaesthesia, Vol. 100, No. 1, 2008, pp. 78-81. doi:10.1093/bja/aem306

[13] N. M. Carneiro, “Acupuntura na Prevençã̃o e Tratamento de Náuseas e Vômitos,” Projeto Diretrizes-Associaçã̃o Médica Brasileira e Conselho Federal de Medicina, 2002. http://www.projetodiretrizes.org.br/projeto_diretrizes/011. pdf

[14] B. Erdur, P. Tura, B. Aydin, M. Ozen, A. Ergin, I. Parlak and B. Kabay, "A Trial of Midazolam vs. Diphenhydramine in Prophylaxis of Metoclopramide-Induced Akathisia,” The American Journal of Emergency Medicine, Vol. 30, No. 1, 2012, pp. 84-91. doi:10.1016/j.ajem.2010.10.007

[15] A. M. El-Deeb and M. S. Ahmady, "Effect of Acupuncture on Nausea and/or Vomiting during and after Cesarean Section in Comparison with Ondansetron," Journal of Anesthesia, Vol. 25, No. 5, 2011, pp. 698-703. doi:10.1007/s00540-011-1198-0

[16] F. S. Pécora, L. M. Malbouisson and M. L. Torres, "Supplemental Oxygen and the Incidence of Perioperative Nausea and Vomiting in Cesarean Sections under Subarachnoid Block,” Revista Brasileira de Anestesiologia, Vol. 59, No. 5, 2009, pp. 558-569. doi:10.1590/S0034-70942009000500004

[17] E. A. Muñoz, F. P. Abizanda, P. R. De Diego and F. Gilsanz Rodríguez, "Ephedrine vs. Phenylephrine by Intravenous Bolus and Continuous Infusion to Prevent Hypotension Secondary to Spinal Anesthesia during Cesarean Section: a Randomized Comparative Trial,” Revista Española de Anestesiología y Reanimación, Vol. 58, No. 7, 2011, pp. 412-416. 